\title{
Calcium Salts Reduce Acrylamide Formation and Improve Qualities of Cookies
}

\author{
Ke- Liang Bruce Chang ${ }^{1}$, Jen-Shiang Wang ${ }^{1}$, Wen-Chieh Sung, ${ }^{1,2 *}$ \\ ${ }^{1}$ Department of Food Science, National Taiwan Ocean University, Keelung, R.O.C \\ ${ }^{2}$ Center of Excellence for the Oceans, National Taiwan Ocean University, Keelung, R.O.C. \\ *Corresponding author: sungwill@mail.ntou.edu.tw
}

Received September 05, 2014; Revised October 20, 2014; Accepted October 31, 2014

\begin{abstract}
This study compares the effects of adding $0.1 \%, 0.5 \%$ and $1.0 \%$ of various calcium salts on the qualities of the model cookies, cookies, and their relation to the reducing sugar content. The highest inhibition of acrylamide formation is obtained by a $1.0 \%$ calcium carbonate fortification of the model cookies (60.47\%). The formation of acrylamide shows a positive correlation with the reducing sugar concentration of these cookies. The reducing sugar of model cookies fortified with calcium carbonate shows the highest correlation with the acrylamide concentration $\left(\mathrm{R}^{2}=0.99\right)$. The reducing sugar content of cookies has the greatest decrease $(54 \%)$ with the addition of $1 \%$ calcium carbonate. The addition of calcium salts, except for calcium carbonate, has significant effect on the appearance and spread ratio of the cookies. The overall acceptability of the fortified cookies is significantly improved by the addition of $1 \%$ calcium carbonate.
\end{abstract}

\section{Keywords: acrylamide, model cookie, reducing sugar, sensory evaluation, calcium carbonate}

Cite This Article: Ke- Liang Bruce Chang, Jen-Shiang Wang, and Wen-Chieh Sung, "Calcium Salts Reduce Acrylamide Formation and Improve Qualities of Cookies." Journal of Food and Nutrition Research, vol. 2, no. 11 (2014): 857-866. doi: 10.12691/jfnr-2-11-16.

\section{Introduction}

Acrylamide is an undesirable chemical compound that is present in heat-processed carbohydrate-rich food products. Decades of toxicological research have indicated that it may not only be a potential human carcinogen, but also a neurotoxin genotoxin [1]. Acrylamide can be generated by nitrogen-containing compounds and oils in food ingredients at a temperature above $100^{\circ} \mathrm{C}$. One study showed that no acrylamide was detected in boiled or unheated foods [2]. Yasahura et al. [3] proposed that the fatty acid oxidation product, acrolein $(\mathrm{CH} 2=\mathrm{CH}-\mathrm{CHO})$, reacted with ammonia to form $\mathrm{CH} 2=\mathrm{CH}-\mathrm{CHOH}(\mathrm{NH} 2)$, which could transform into acrylamide by oxidation or by reacting with asparagine to form a N-glycoside, and then transform into acrylamide by oxidation. On the other hand, Zyzak et al. [4] proposed a mechanism for the generation of acrylamide from the reaction of a carbonyl-containing compound and asparagines in fried mid oleic sunflower oil at a temperature of $205^{\circ} \mathrm{C}$. Food heated at a high temperature has been proposed as the main source of acrylamide for consumers [5]. Acrylamide can also be produced by rearrangement of the nitrogen-containing components present in heated foodstuffs [6]. The major pathway of acrylamide generation is associated with the Maillard reaction [7,8]. A large quantity of acrylamide $(150-4000 \mu \mathrm{g} / \mathrm{kg})$ can be found in baked starchy and fried foods [2]. To seek an effective way to reduce acrylamide formation in baked goods is an urgent issue for the baking industry.

Asparagine has been shown to be the key precursor of acrylamide by Strecker degradation in the Maillard reaction $[6,8,9]$. The presence of asparagines or fructose and glucose at certain concentrations ( $38 \mathrm{mM}$ fructose and $56 \mathrm{mM}$ glucose) enhances the formation of acrylamide [10]. Other amino acids, including alanine, arginine, aspartic acid, cysteine, glutamine, methionine, threonine and valine, have generated only small amounts of acrylamide in similar laboratory-heated foods [2]. In general, heat-processed commercial protein-rich foods, such as fish, meat and poultry, contain lower amounts of acrylamide than carbohydrate-rich foods, such as French fries, potato chips, tortilla chips, various cereals and baked goods, processed at a high temperature [2]. The Schiff base formation is considered to be the first reaction step. The initial reaction is the addition of the nucleophilic asparagines to the partially positive carbonyl carbon of the dicarbonyl compound, and then the loss of a proton from the nitrogen and the gain of a proton by the oxygen [8]. The presence of polyvalent cations, such as calcium ions, reduced the acrylamide formation during heating [11]. Jung et al. [12] proposed that the conversion of free nonprotonated amine to nonnucleophilic protonated amine could be achieved by lowering the $\mathrm{pH}$ of a food system. Therefore, lowering the $\mathrm{pH}$ of cookies could effectively reduce the acrylamide formation.

Practical strategies to mitigate the formation of acrylamide in processed foods have been explored in recent years, including adding divalent cations, such as 
calcium salts $[13,14]$, substituting reducing sugars with sucrose $[15,16,17]$, adding glycine to dilute the asparagine level [18], reducing the free asparagine concentration by asparaginase $[19,20]$ and replacing ammonium salts with baking powder [21].

Investigating the acrylamide formation during the baking process and its effect on the various ingredients could help the food industry design more effective methods to reduce the formation of acrylamide in bakery products. Jung et al. [12] demonstrated that the formation of acrylamide in baked and fried corn chips and French fries was reduced by adding an acidulant to lower their $\mathrm{pH}$ values. Ammonium bicarbonate, a chemical leavening, strongly enhanced the formation of acrylamide [17]. In addition, the use of sodium bicarbonate as a chemical leavening agent reduced the formation of acrylamide by over 60\%. Amrein et al. [17] suggested that free asparagine was a limiting factor for acrylamide formation. Consequently, the acrylamide content could be lowered by replacing reducing sugars with sucrose or by adding organic acids.

To understand the interactions that occur in a cookie formulation with reducing sugar and shortening, we used a model cookie recipe with no added shortening, nonfat dry milk, sodium chlorine, high-fructose corn syrup and ammonium bicarbonate to study the role of calcium salts and reducing sugars in the formation of acrylamide. Making the model cookies with no shortening or with fortified calcium salts as supplements and reducing sugars associated with the formation of acrylamide allowed for the effect on the cookies to be thoroughly studied. In this study, different types of calcium salts as calcium supplements for reducing the formation of acrylamide in the model cookies without shortening and their relation to the reducing sugar content were also investigated. The quality characteristics of the model cookies and the cookies fortified with calcium salts were also evaluated to develop better strategies to reduce the acrylamide content of baked products.

\section{Materials and Methods}

\subsection{Raw Materials and Chemicals}

Cake flour was obtained from the Cha Hwa Corporation (Taichung, Taiwan). Sucrose, brownulated granulate sucrose, non-fat dry milk, sodium chloride, sodium bicarbonate, shortening, high-fructose corn syrup (HFCS 55) and ammonium bicarbonate (food grade) were purchased from the $\mathrm{Fu}$ Shen baking ingredient store (Keelung, Taiwan). A dynamic light-scattering analyzer (System 4700c sub-micron particle analyzer, Malvern Instrument, Worcestershire, UK) was used to measure particle size.

D-glucose, sulphuric acid, 3,5-dinitrosalicylic acid, potassium sodium tartrate and sodium hydroxide were purchased from Sigma Aldrich (St. Louis, Missouri, USA). All reagents used were of analytical grade. Standard chemical compound acrylamide 99.9\% was purchased from J.T. Baker (Phillipsburg, NJ, USA). Oasis MCX (3 $\mathrm{ml}, 60 \mathrm{mg}$ ) and Oasis HLB (6 ml, $200 \mathrm{mg}$ ) solid phase extraction (SPE) cartridges were supplied by Waters (Milford, MA, USA).

\subsection{Physicochemical Properties of Cookies and Cookie Preparation}

The formula for the model cookie was as follows: 80.0 $\mathrm{g}$ cake flour, $17.6 \mathrm{~g}$ deionized water and $34.8 \mathrm{~g}$ brownulated sucrose (Table 1). The model cookie base recipe was modified by the addition of calcium salts $(0.1 \%$, $0.5 \%$ and $1.0 \%$ ). The formula of the cookie was as follows: $80.0 \mathrm{~g}$ cake flour, $17.6 \mathrm{~g}$ deionized water, $25.6 \mathrm{~g}$ sucrose, $8.0 \mathrm{~g}$ brownulated sucrose, $0.8 \mathrm{~g}$ non-fat dry milk, $1.0 \mathrm{~g}$ sodium chloride, $0.8 \mathrm{~g}$ sodium bicarbonate, $32.0 \mathrm{~g}$ allpurpose shortening, $1.2 \mathrm{~g}$ high fructose corn syrup and 0.4 g ammonium bicarbonate (Table 1). The cookie base recipe was supplemented by the addition of calcium salts (calcium lactate, calcium citrate, calcium acetate and calcium carbonate). Three levels of calcium supplement $(0.1 \%, 0.5 \%$ and $1.0 \%$ of elemental calcium in cake flour weight basis) were added to formula of model cookie and formula of cookie. The formula for the model cookies was modified from the American Association of Cereal Chemists (AACC) method 10-54 [22]. Sucrose and high fructose corn syrup in the AACC cookie formula were replaced with brownulated sucrose in the model cookie. The cookie dough was rolled out to a thickness of $2 \mathrm{~mm}$ and cut with a circular cookie cutter (diameter: $60 \mathrm{~mm}$ ). The cookie dough was baked in an electric oven (Chung $\mathrm{Pu}$ Baking Machinery Co., LTD, Taichung, Taiwan) at $205^{\circ} \mathrm{C}$ for 10 minutes. The total diameter and thickness of ten cookie samples after baking were measured using a Venier Caliper. The cookie spread ratio was calculated by dividing the diameter with the thickness of the cookie. The effect of calcium salts on the $\mathrm{pH}$ of the cookie was measured by the method of Hwang et al. [23], with a slight modification. The ash content of the cookie was measured according to AACC procedure 46-12 [22]. The water activity of the cookie was determined using a Thermoconstanter Novasina RTD 33 TH-1 avumeter (Novasina Co. Ltd., Pfaffikon, Switzerland). Three grams of refrigerated mashed cookie sample were put in the sample box to equilibrate to room temperature for 1 hour before measurement.

Table 1. Formula of cookies and model cookies

\begin{tabular}{ccc}
\hline & Cookie & Model cookie \\
\hline Ingredients & Weight (g) & Weight (g) \\
\hline Sucrose & 25.6 & 34.8 \\
Nonfat dry milk & 8.0 & \\
NaCl & 0.8 & \\
Sodium bicarbonate & 1.0 & \\
All-purpose shortening & 0.8 & \\
High-fructose corn syrup & 32.0 & \\
Anunonium bicarbonate & 1.2 & \\
Deionized water & 0.4 & \\
Flour & 17.6 & \\
\hline
\end{tabular}




\subsection{Method for Measuring Acrylamide in Cookies}

Cookies were ground with a pulverizer (D3V-10, Yu Chi Machinery Co., Ltd., Chang Hua, Taiwan) and 2 g were weighed and put into a centrifuge tube $(50 \mathrm{ml})$. Then, $15 \mathrm{ml}$ of deionized, distilled water was added and mixed in a $50^{\circ} \mathrm{C}$ reciprocal shaker bath for $60 \mathrm{~min}$. The mixture was centrifuged at $9000 \mathrm{rpm}$ for $20 \mathrm{~min}$ at $5^{\circ} \mathrm{C}$. The supernatant was filtered through a nylon filter $(0.45 \mu \mathrm{m})$. The HLB/MCX cartridge was conditioned with $5 \mathrm{ml}$ and 3 $\mathrm{ml}$ methanol followed by $5 \mathrm{ml}$ and $3 \mathrm{ml}$ of de-ionized, distilled water, respectively. Filtrate $(1.5 \mathrm{ml})$ was then passed through the Oasis HLB/MCX cartridge to absorb acrylamide, and the filtrate was discarded. The cartridge was washed with $0.5 \mathrm{ml}$ de-ionized, distilled water and the filtrate was discarded again. The cartridge was washed with $3.0 \mathrm{ml}$ of de-ionized, distilled water and the eluent was collected in a glass tube. The eluent was concentrated under vacuum for HPLC analysis.

Acrylamide levels of the cookies and the model cookies were determined using the HPLC method [7]. The HPLC system (D2000) consisted of an L-2130 pump, L-2400 detector, L-2300 column oven and an L-2200 autosampler (Merck, Hitachi, Kent, UK). Chromatographic separation was performed on a Capcell Pak $\mathrm{C}_{18}$ AQ S5 column ( $5 \mu \mathrm{m}$, $4.6 \mathrm{~mm} \times 250 \mathrm{~mm}$ ) (Shiseido, Tokyo, Japan) using deionized, distilled water at a flow rate of $0.7 \mathrm{ml} / \mathrm{min}$ at $25^{\circ} \mathrm{C}$. Mobile phase: $100 \%$ double distilled water. Injection volume: $20 \mu \mathrm{l}$.

\subsection{Assay for Reducing Sugars}

A finely ground cookie sample $(0.1 \mathrm{~g})$ was added to 10 $\mathrm{ml}$ of $1.5 \mathrm{M}$ sulphuric acid and heated in a boiling water bath for $20 \mathrm{~min}$. Once cooled, $12 \mathrm{ml}$ of $10 \%$ sodium hydroxide was added. The solution was filtrated and made up to $100 \mathrm{ml}$ with deionized, distilled water. Standard glucose solution was used in the assay for reducing sugar. The quantitative determination of reducing sugars was measured by a dinitrosalicylic acid reducing sugar assay using the method of Ilyina et al. [24] with slight modification.

\subsection{Determination of Cookie Colour and Browning Index}

Cookie colour was examined using a spectrocolorimeter (TC-1800 MK II, Tokyo, Japan) using the L* (lightness), $\mathrm{a}^{*}$ (redness/greenness) and $\mathrm{b}^{*}$ (yellowness/blueness) colour scale. Both a white tile and a black cup were examined before the test to standardize the spectrocolorimeter. The colour of the cookies was recorded with three measurements for each sample and triplicate determinations were recorded per treatment. Colour difference $\Delta \mathrm{E}$ was calculated using the following equation:

$$
\Delta \mathrm{E}=\left[\left(\Delta \mathrm{L}^{*}\right)^{2}+\left(\Delta \mathrm{a}^{*}\right)^{2}+\left(\Delta \mathrm{b}^{*}\right)^{2}\right]^{1 / 2}
$$

where $\quad \Delta \mathrm{L}^{*}=\mathrm{L}^{*}$ sample $-\mathrm{L}^{*}{ }_{\text {control }} ; \Delta \mathrm{a}^{*}=\mathrm{a}^{*}{ }_{\text {sample }}-\mathrm{a}{ }^{*}{ }_{\text {control }}$; $\Delta \mathrm{b}^{*}=\mathrm{b}^{*}{ }_{\text {sample }}-\mathrm{b}^{*}$ control.

The brown index (WI) was calculated using the follow equation:

$$
\mathrm{BI}=100 *[\mathrm{x}-0.31] / 0.17
$$

where $\mathrm{x}=\left(\mathrm{a} *{ }_{\text {sample }}+1.75 \mathrm{~L} *{ }_{\text {sample }}\right) /\left(5.645 \mathrm{~L} *{ }_{\text {sample }}+\mathrm{a} *{ }_{\text {sample }}\right.$ $-3.012 b *$ sample).

The $\mathrm{L}^{*}$ sample, $\mathrm{a}^{*}$ sample and $\mathrm{b}^{*}$ sample values correspond to the Commission Internationale de I'Eclairage (CIE) colour parameters of the cookies made with different amounts $(0.1 \%, 0.5 \%$ and $1.0 \%)$ of calcium salts.

\subsection{Textural Characteristics of Cookies}

Breaking force, breaking point and the work of breaking the cookies after baking were measured by compression with the TA.XT 2 Texture Analyzer (Stable Micro System, Godalming, Surrey, UK) with a load cell of $5 \mathrm{~kg}$. A special pasta blade and plate (probe TA 47, 60 $\mathrm{mm} \times 20 \mathrm{~mm}$ ) were used to imitate the biting action of a tooth. The breaking force was expressed as the maximum force (g) of the blade with a speed of $10 \mathrm{~mm} / \mathrm{s}$ required to cut the cookie to a depth of $200 \mathrm{~mm}$. The trigger force was 20 g. Ten measurements were made per tested group.

\subsection{Sensory Evaluation of Cookies Fortified with Calcium Carbonate}

Cookies made with the addition of calcium carbonate $(0.1 \%, 0.5 \%$ and $1.0 \%)$ were served to untrained sensory panellists who were to evaluate the aroma, colour, texture, sweetness and overall scores. Fifty-six students were instructed to evaluate each attribute using a seven-point hedonic scale ranging from "1=dislike extremely" to "7=like extremely." Eighteen male and thirty-eight female students and faculty members of the Department of Food Science were between the ages of 20 and 44 were participants on the panel. Cookie samples coded with three digits were served to the panellists. Each data point from the sensory analysis represents an average of 56 panellists.

\subsection{Statistical Analysis}

A completely randomized block design was used with three replications per treatment. Data were analyzed by analysis of variance using the SPSS statistic program (SPSS, 1.2, 1998). Duncan's multiple range test was used to identify the difference between treatments at a $5 \%$ significance level $(\mathrm{p}<0.05)$.

\section{Results and Discussion}

\section{1. pH of Cookie and Dough}

The $\mathrm{pH}$ of the model cookie and the model cookie dough was 5.83 and 5.94, respectively (Figure 1). The addition of calcium lactate into the model cookie dough formulations decreased the $\mathrm{pH}$ of model cookies; nevertheless, the addition of calcium citrate, calcium acetate and calcium carbonate increased the $\mathrm{pH}$ of the model cookie dough (Figure 1A). The $\mathrm{pH}$ of the cookie and the model cookie decreased slightly after baking (Figure 1 \& Figure 2) comparing to the $\mathrm{pH}$ of cookie dough and model cookie dough. This may have been because the amino group reacted with a carbonyl source in the cake flour under heat during the Maillard reaction, resulting in the elimination of water. Hydrogen ions were 
released by the Amadori rearrangement, which decreased the $\mathrm{pH}$ of the cookie and the model cookie. Clawson and Taylor [25] reported that the $\mathrm{pH}$ decreased from the initial $\mathrm{pH}$ values of 6.12 and 7.81 to 5.88 and 6.32, respectively, when ground wheat samples were cooked in sealed glass ampoules for $70 \mathrm{~min}$ at $121^{\circ} \mathrm{C}$. Hamlet and Sadd [26] also showed that the $\mathrm{pH}$ dropped from 5.91 to 4.73 in a pressure-cooking apparatus at $180^{\circ} \mathrm{C}$ for 20 min using a basic flour, water and salt dough model system. Reductions in $\mathrm{pH}$ were attributed to the Maillard reaction [27].

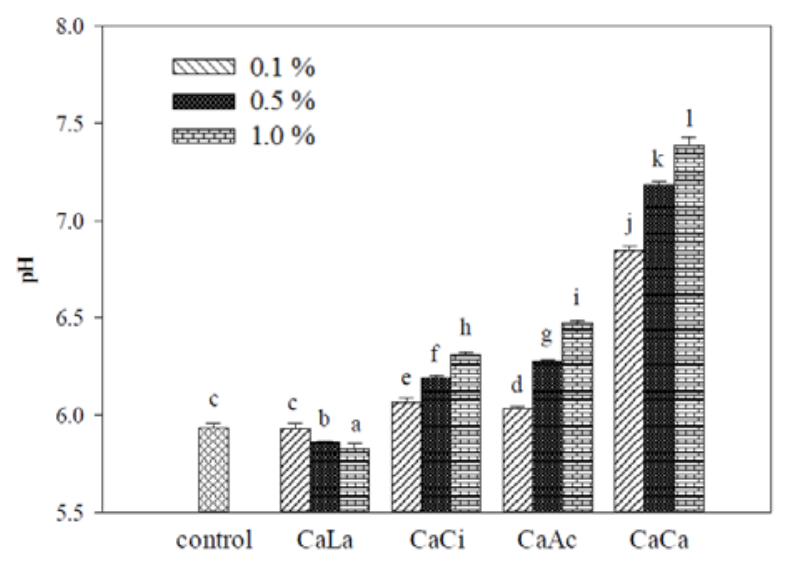

A Model cookie doughs

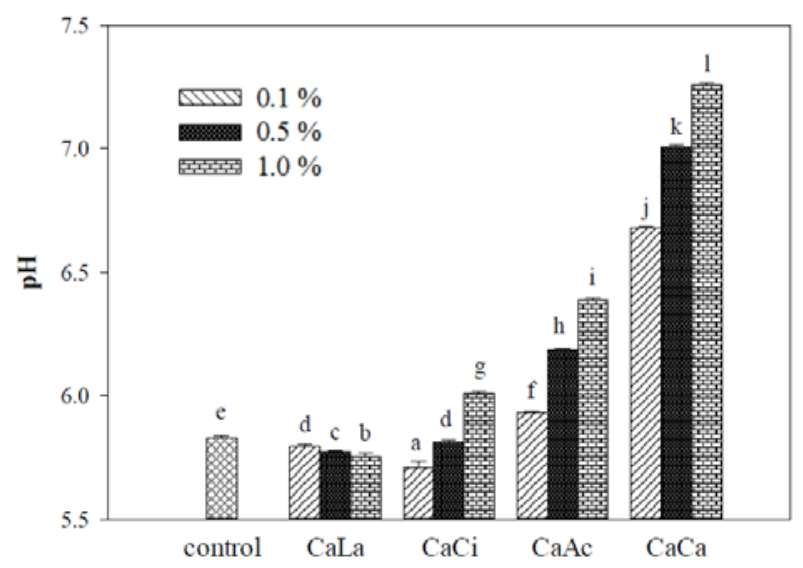

B Model cookies

Figure 1. Effect of various amounts of calcium salts on the $\mathrm{pH}$ of model cookies dough (A) and model cookies (B)

CaLa. Calcium lactate; CaCi. Calcium citrate; CaAc. Calcium acetate; CaCa. Calcium carbonate.

${ }^{\text {a-i }}$ Indicate significant difference between different ainounts of calcium salts. $(\mathrm{n}=3 ; p<0.05)$

The $\mathrm{pH}$ of all cookies with calcium salts decreased after baking in comparison to the control cookies (Figure 2B). In general, cookies fortified with a high amount of calcium salts had a lower $\mathrm{pH}$ after baking. The divalent calcium ion was able to induce a significant $\mathrm{pH}$ decrease in the cookie dough, and the lowering of the $\mathrm{pH}$ was accompanied by a reduction in acrylamide formation [27]. It has been suggested that the phenomenon of calcium ioninduced $\mathrm{pH}$ lowering is a result of the competitive displacement of protons from ionisable oxygen, nitrogen or sulphur atoms which share electrons with hydrogen atoms. As a consequence, mass action competition occurs between protons and calcium ions when the $\mathrm{pH}$ is high enough, but when the $\mathrm{pH}$ is not so high, most protons would have been removed prior to the adding of the calcium ions [28].

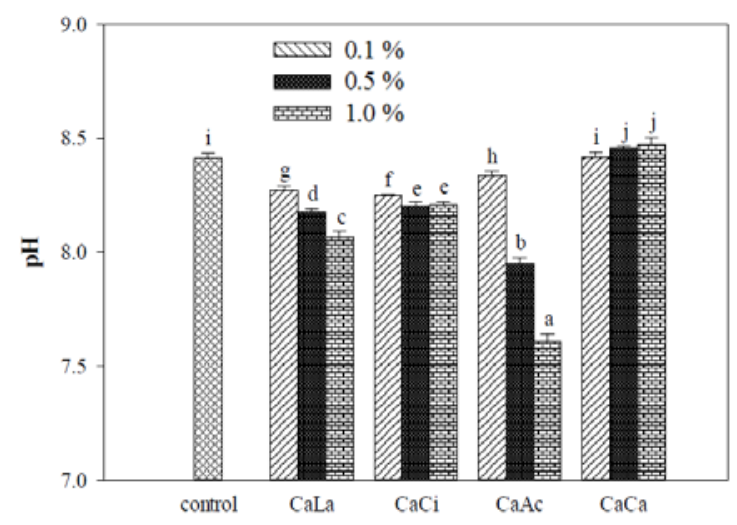

A Cookie doughs

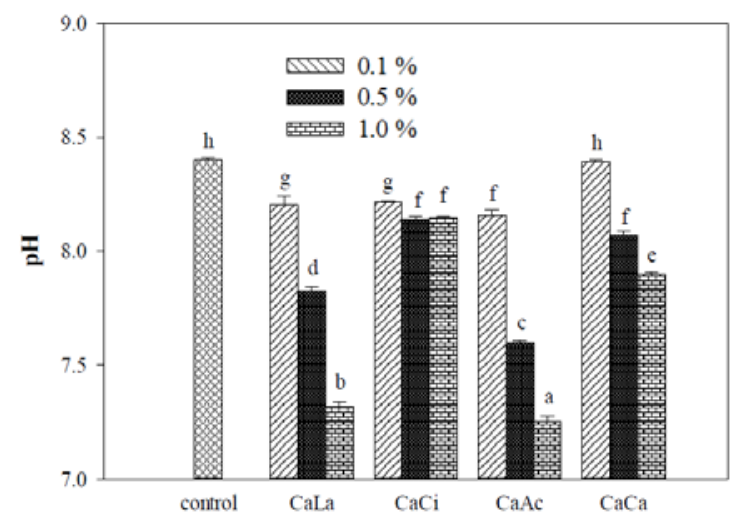

B Cookies

Figure 2. Effect of various amounts of calcium salts on the $\mathrm{pH}$ of cookie dough (A) and cookies (B)

CaLa, Calcium Lactate; CaCi, Calcmm Citrate: CaAc. Calcium acetate; CaCa. Calcium carbonate.

${ }^{\mathrm{iVJ}}$ Indicate significant difference between different amounts of calcmm salts. $(n=3 ; p<0.05)$

\subsection{Addition of Calcium Salts on the Formation of Acrylamide}

The acrylamide concentration in the model cookies treated with $0,0.1 \%, 0.5 \%$ and $1.0 \%$ calcium lactate was detected by the HPLC analytic method. The model cookies and cookies (no calcium salts treated) contained $1089.36 \mathrm{ng} / \mathrm{g}$ and $718.33 \mathrm{ng} / \mathrm{g}$ acrylamide, respectively (Figure 3). Model cookies treated with $0.1 \%, 0.5 \%$ and $1.0 \%$ calcium lactate contained $1027.79 \mathrm{ng} / \mathrm{g}, 846.90 \mathrm{ng} / \mathrm{g}$ and $656.88 \mathrm{ng} / \mathrm{g}$ acrylamide, indicating that calcium lactate fortification induced inhibition of acrylamide formation (Figure 3A). The acrylamide content in the $0.1 \%, 0.5 \%$ and $1.0 \%$ calcium lactate-treated model cookies and cookies were significantly lower than that of the control model cookies and the control cookies $(\mathrm{p}<0.05)$ (Figure 3). Of the calcium salts used in this study, calcium lactate was the least effective in terms of preventing the formation of acrylamide. The addition of organic acid to cookie recipes might enhance the formation of acrylamide due to the hydrolysis of sucrose to reducing sugar $[15,16]$. The reducing sugar content in the model cookies of calcium lactate fortification was higher than that of those 
fortified with other calcium salts (Figure 4A). However, calcium lactate was still able to significantly mitigate the formation of acrylamide.

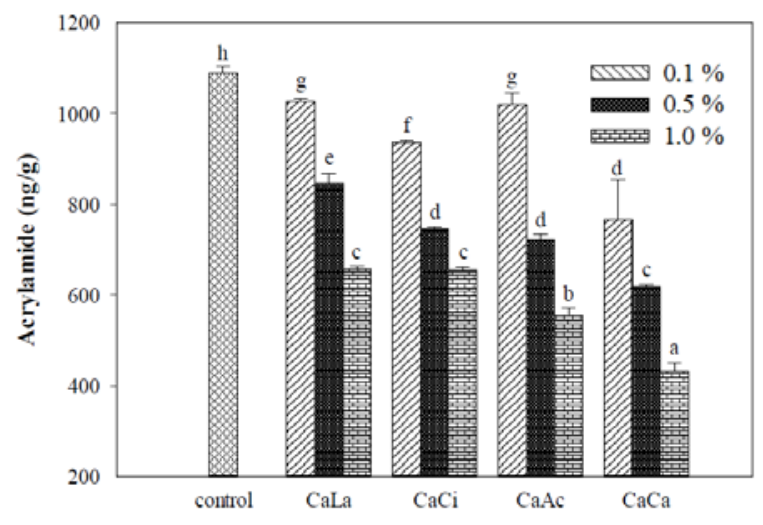

A Model cookies

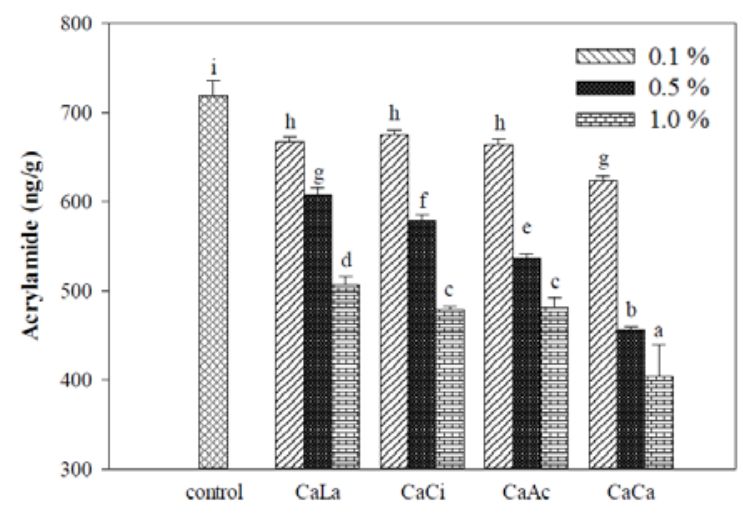

B Cookies

Figure 3. Effect of various amounts of calcium salts on the acrylamide of model cookies (A) and cookies (B)

CaLa, Calcium lactate; CaCi, Calcium citrate; CaAc, Calcium acetate; CaCa, Calcium carbonate.

${ }^{\mathrm{a}-\mathrm{i}}$ Indicate significant difference between different amounts of calcium salts. $(\mathrm{n}=3 ; \mathrm{p}<0.05)$

Figure 3 shows that the acrylamide concentration of the model cookies was higher than that of the cookies. This may have been because the model cookie formula used more brownulated sucrose, which contained more reducing sugar (Figure 3A) than sucrose, a non-reducing sugar (Figure 3B). The acrylamide concentration in the cookies as reported by Acar et al. [7] was $128 \mathrm{ng} / \mathrm{g}$ acrylamide, which was lower than that of our data, and may have been due to the difference in cookie thickness. In their study, the dough was rolled out to a thickness of 1 $\mathrm{cm}$, while in our experiments the dough was rolled out to a thickness of $0.2 \mathrm{~cm}$. Thinner cookie dough would be baked at a higher temperature and so increase the amount of acrylamide formed in the cookies. The addition of calcium carbonate significantly decreased the acrylamide formation in model cookies and cookies $(\mathrm{p}<0.05)$ (Figure 3 ). The acrylamide concentration of the model cookies fortified with $0.1 \%, 0.5 \%$ and $1.0 \%$ of calcium carbonate were $766.2 \mathrm{ng} / \mathrm{g}, 619.1 \mathrm{ng} / \mathrm{g}$ and $430.6 \mathrm{ng} / \mathrm{g}$ acrylamide, respectively (Figure 3A). These results represented a dramatic decrease in the formation of acrylamide when the amount of calcium carbonate was $0.1 \%$ in the model cookie and cookie formulation. In comparison, for the control model cookies and cookies, the decrease in acrylamide content for $0.1 \%$ calcium carbonate fortification was $30 \%$ and $13 \%$, respectively (Figure 3). In the model cookies, decreases of $30 \%$ and $60 \%$ in the acrylamide concentrations were for $0.1 \%$ and $1.0 \%$ calcium carbonate fortification, respectively (Figure 3A). Acar et al. [7] showed that calcium salts significantly decreased the acrylamide formation in cookies. Gokmen and Senyuva [14] also reported that adding calcium ions enhanced the high-temperature stability in asparagines/matrix interactions, thus blocking the asparagines from reacting with carbonyl precursors to form acrylamide during the Maillard reaction. Sadd et al. [29] found that fortification of bread dough with different calcium salts was able to reduce the formation of acrylamide.

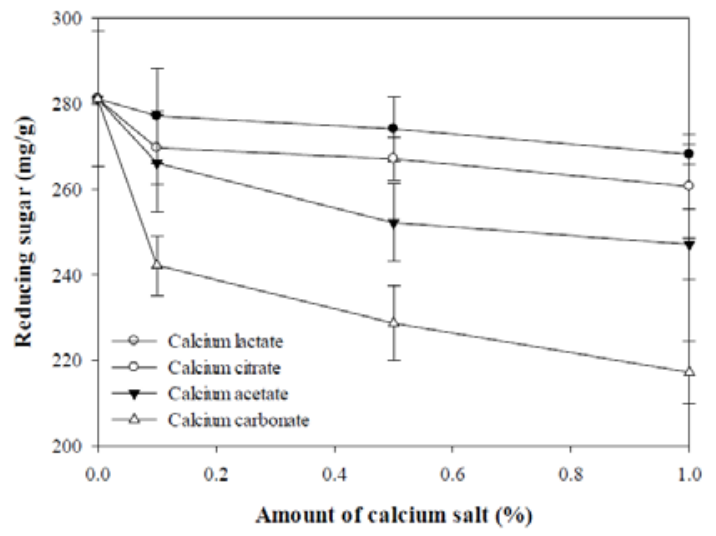

A Model cookies

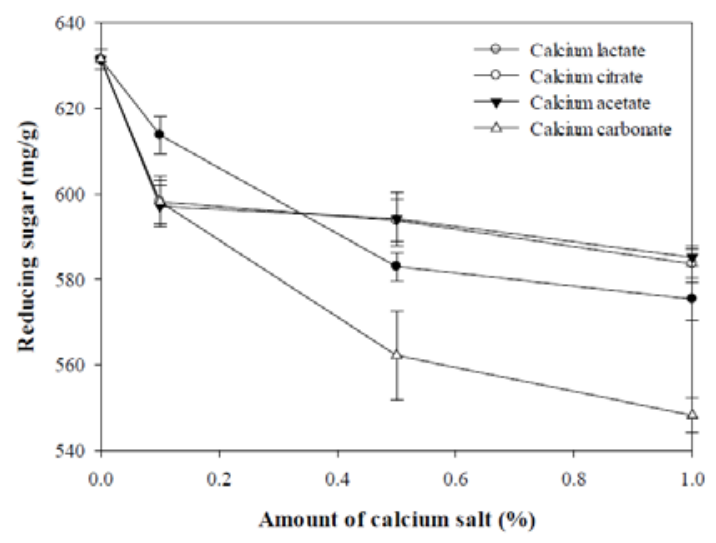

B Cookies

Figure 4. Effect of various amounts of calcium salts on reducing sugar concentration of model cookied (A) And cookies (B)

Of the calcium salts tested in this study, calcium lactate was the least effective in preventing the formation of acrylamide, although it lowered the $\mathrm{pH}$ of the cookies and the dough. Lowering the $\mathrm{pH}$ seemed less important than the addition of calcium salt types for the mitigation of acrylamide formation. Acar et al. [7] observed that a lower amount of calcium and a higher amount of lactate increased acrylamide formation.

In this study, shortening was not added to the model cookie formula, as it was designed to eliminate the possibility of acrylamide formation arising from the reaction between oils and nitrogen-containing compounds. Our results showed that the model cookies with no shortening added had higher acrylamide concentrations 
than cookies made with shortening added (Figure 3). Therefore, acrylamide could be generated primarily from the rearrangement of nitrogen-containing compounds and reducing sugar in cookies without shortening. The results demonstrated that the cookies with added shortening could reduce gluten formation during mixing, due to no blister or shell shape formed on the surface of cookies. The model cookies without shortening formed blister or shell shapes after baking, an indication that gluten formed a partial network structure during mixing.

\subsection{Reducing Sugar in Model Cookies and Cookies Fortified with Calcium Salts}

Adding calcium salts decreased the amount of reducing sugar in model cookies and cookies (Figure 4). Gokmen and Senyuva [14] reported that when the concentration of calcium cations was increased, the amount of reducing sugar and glucose decreased. The significant decrease in the amount of reducing sugar in the model cookies and cookies was observed upon the addition of calcium carbonate (Figure 4). Gokmen and Senyuva [11] demonstrated that the presence of calcium cations reduced the acrylamide concentration by increasing furfural and hydroxymethyl furfural concentration. They postulated that the key intermediate, Schiff base, for acrylamide formation was inhibited and shifted to another reaction pathway, with the dehydration of glucose leading to hydroxylmethyl furfural and furfural [11]. Therefore, the presence of calcium ions reduced the amount of reducing sugar and acrylamide formation by inducing the formation of hydroxymethylfurfural and furfural. Rydberg et al. [10] confirmed that the presence of asparagines and at $38 \mathrm{mM}$ fructose or $56 \mathrm{mM}$ glucose concentrations could increase the acrylamide concentration of heated foods.

The acrylamide concentration in the model cookies with $0.1 \%, 0.5 \%$ and $1.0 \%$ calcium acetate fortification was $1020.0 \mathrm{ng} / \mathrm{g}, 721.7 \mathrm{ng} / \mathrm{g}$ and $555.0 \mathrm{ng} / \mathrm{g}$ acrylamide, respectively. This corresponded to the $6 \%$, 34\% and $49 \%$ mitigation of acrylamide formation by $0.1 \%, 0.5 \%$ and $1.0 \%$ calcium acetate fortification, respectively (Figure 3A). The acrylamide concentrations among the fortified model cookies were significantly different $(\mathrm{p}<0.05)$. The results demonstrated that $0.1 \%, 0.5 \%$ and $1.0 \%$ calcium acetate fortification greatly inhibited the formation of acrylamide in the model cookies during baking.

The use of calcium citrate also decreased acrylamide formation in the model cookies. The amount of calcium citrate significantly reduced the formation of acrylamide in cookies $(\mathrm{p}<0.05)$. In comparing the model cookies and cookies, the acrylamide content showed a $6 \%$ and a $14 \%$ reduction for $0.1 \%$ calcium citrate fortification, respectively. The acrylamide contents decreased to 654.2 ng/g and 478.9 ng/g acrylamide in model cookies and cookies when the addition of calcium citrate was increased to $1 \%$ (Figure 3 ).

\subsection{Correlation between the Content of Reducing Sugar and Acrylamide}

Correlation was tested using individual calcium salt, calcium lactate $\left(\mathrm{R}^{2}=0.97\right)$, calcium citrate $\left(\mathrm{R}^{2}=0.81\right)$, calcium acetate $\left(R^{2}=0.99\right)$ and calcium carbonate $\left(R^{2}=0.99\right)$ in different amounts (Figure 5A). Figure 6 shows the correlation between acrylamide concentration and reducing sugar in the model cookies and cookies fortified with various calcium salts. The predicted equation was used to make predictions of the acrylamide level, as the reducing sugar content of the model cookies and cookies was obtained. The formation of acrylamide showed a positive relationship with the reducing sugar concentration of the calcium salt fortified model cookies $\left(\mathrm{R}^{2}=0.58\right)$. As Figure 6A shows, the predicted relation between the level of acrylamide formation and reducing sugar concentration was based on four calcium salts. As the ingredients and baking conditions are normally kept constant in the baking industry, the reducing sugar concentration in the model cookies could be used to predict acrylamide formation. The regression equation for the correlation is as follows: acrylamide concentration (ng/g) $=82.04 *$ reducing sugar content (mg/g) -1340.8. The predictability of acrylamide was also reported by Amrein et al. [17]. Among the correlations between reducing sugars and acrylamide level, the model cookies fortified with calcium carbonate and calcium acetate showed the highest correlation with the acrylamide concentration.

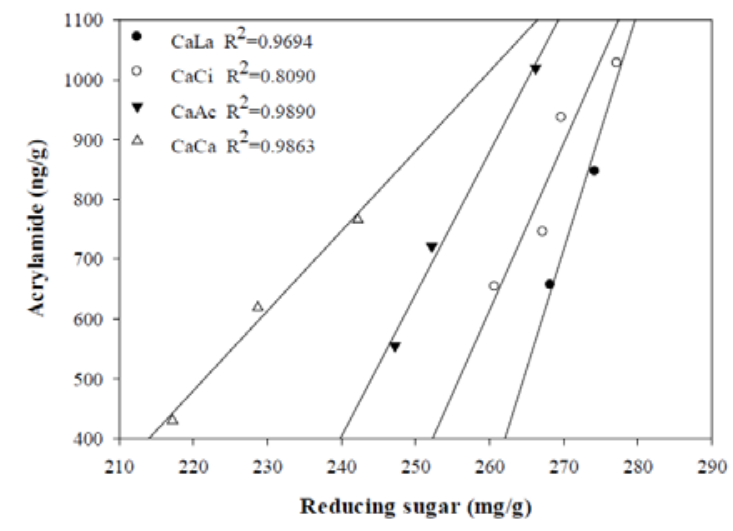

A Model cookies

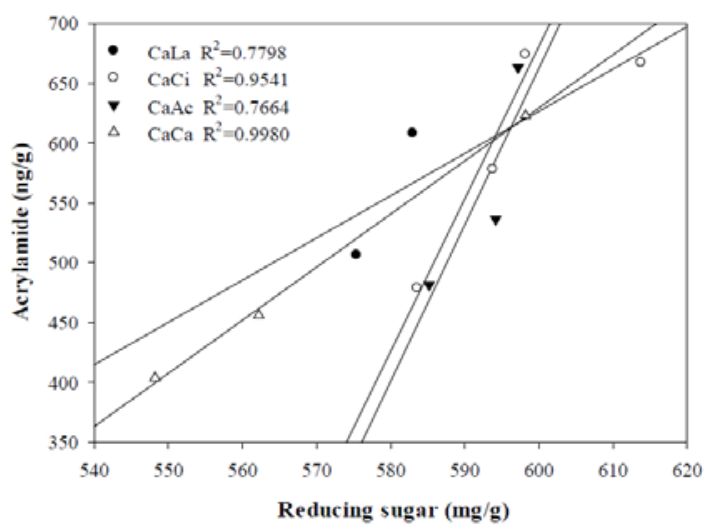

B Cookies

Figure 5. The correlation between aciylainicle and reducing sugar content of calcium fortified model cookies (A) and cookies (B).

CaLa, Calcium lactate; CaCi. Calcium citrate; CaAc, Calcium acetate; CaCa, Calcium carbonate.

Figure 6B shows the correlation equations for cookies formulated with reference to the AACC method. These equations could serve as a practical tool for the baking industry, by making it easier to predict the formation of acrylamide based on the reducing sugars and calcium salt fortification. The formation of acrylamide showed a 
positive relationship with the reducing sugar concentration of calcium salt-fortified cookies $\left(\mathrm{R}^{2}=0.78\right)$. The correlation can be described by the following equation: acrylamide concentration (ng/g) $=41.31 *$ reducing sugar content (mg/g) -1866.8 (Figure 6B). However, the correlation coefficients were lower than those of the model cookies. For the cookies fortified with different calcium salts, the correlation coefficients were calcium lactate $\left(R^{2}=0.78\right)$, calcium citrate $\left(R^{2}=0.95\right)$, calcium acetate $\left(R^{2}=0.77\right)$ and calcium carbonate $\left(R^{2}=0.99\right)$, respectively (Figure 5B). The lower correlation could have been because more ingredients in the cookie recipe influenced the level of acrylamide formation. The reducing sugar of cookies fortified with calcium carbonate showed the highest correlation with the acrylamide concentration $\left(\mathrm{R}^{2}=0.99\right)$. This may have been because calcium carbonate cannot be easily dissolved in water. The regression equation established for the cookie baking could possibly serve as a simple predictive method to determine the mitigation of acrylamide formation within the tested concentrations. Once the reducing sugar concentration is measured, the acrylamide could be reduced by selecting calcium salts under a minimum amount of reducing sugars or by increasing the concentration of calcium salt fortification during the formula's design.

\subsection{Physicochemical Properties of Model Cookies and Cookies with Calcium Supplements}

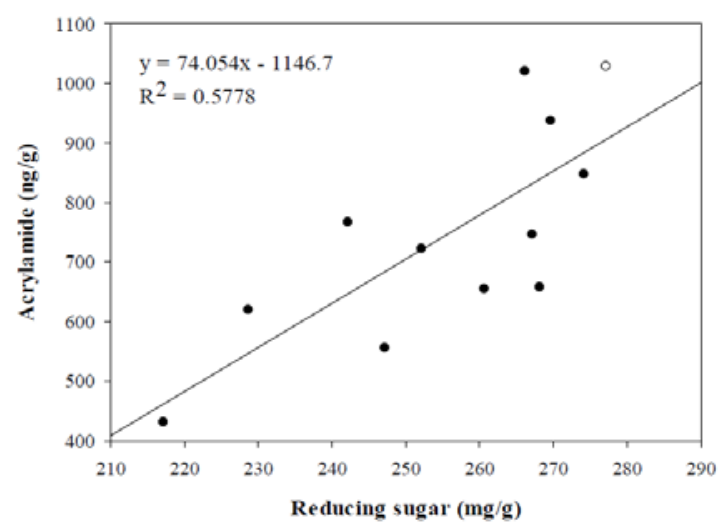

A Model cookies

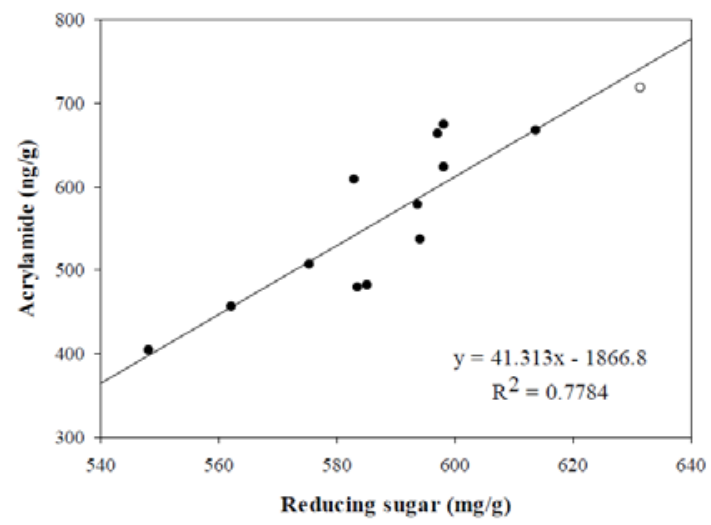

B Cookies

Figure 6. The correlation between aciylainicle and reducing sugar content of calcium fortified model cookies (A) and cookies (B).
Fortification of the model cookies with different amounts of various calcium salts had no significant effect on cookie diameter. The thickness of the model cookies was incomparable due to the irregular shell shapes which formed on the surface. In general, the diameter and thickness of the cookies decreased with an increase in calcium salts (Table 2). The only exception was that the diameter of the calcium lactate-fortified cookies increased with an increase in calcium. As a result, the addition of calcium lactate increased the diameter of the cookies, perhaps because the low $\mathrm{pH}$ and small particle size caused low viscosity cookie dough to form, which resulted in an enhanced cookie spread during the baking process.

The particle sizes of calcium lactate, calcium citrate, calcium acetate and calcium carbonate were $451.0 \mathrm{~nm}$, $2630.5 \mathrm{~nm}, 885.6 \mathrm{~nm}$ and $1877.0 \mathrm{~nm}$, respectively. The spread ratio of the calcium-fortified cookies showed a negative relation to the particle size of calcium salts $\left(\mathrm{R}^{2}=0.90\right)$. The hardness of the cookies fortified with calcium salts was higher than that of the control cookies, indicating that a strong binding strength developed when a better gluten network formed after the calcium salts were added. Calcium salts can toughen cookie dough by interacting with gluten and extending dough development.

Table 2. Effect of different amounts of calcium salts on the spread of cookies

\begin{tabular}{|c|c|c|c|c|}
\hline \multicolumn{5}{|c|}{${ }^{\text {a-J }}$ Values with the different letters within the same column are } \\
significantly different
\end{tabular}

Obvious changes in the spread ratio and colour of calcium lactate-fortified cookies were observed as the cookies were prepared. There were differences in the colour values of cookies and that of model cookies. Lower $\mathrm{L}^{*}, \mathrm{~b}^{*}$ and higher brown index values of model cookies fortified with calcium lactate and calcium acetate were found as compared to the control model cookies (Table 3). 
Table 3. CIE $\mathrm{L}^{*} \mathbf{a}^{*} \mathbf{b}$ values of model cookies fonnulated with different amounts of various calcium salts

\begin{tabular}{|c|c|c|c|c|c|c|}
\hline Model cookie & & $\mathrm{I}^{*}$ & & $b^{*}$ & Total colour difference (AE) & Brown index (BI) \\
\hline \multicolumn{2}{|c|}{ Control model cookies } & $43.79 \pm 1.37^{\mathrm{e}}$ & $1.87 \pm 0.49^{f}$ & $26.40 \pm 0.65^{\mathrm{fg}}$ & 0.00 & 89.52 \\
\hline $\mathrm{C}$ alciuin & $0.1 \%$ & $42.31 \pm 1.30^{\mathrm{d}}$ & $1.90 \pm 0.41^{\mathrm{fg}}$ & $25.60 \pm 0.59^{c}$ & 2.39 & 91.91 \\
\hline \multirow[t]{2}{*}{ lactate } & $0.5 \%$ & $41.45 \pm 1.17^{\mathrm{c}}$ & $2.07 \pm 0.31^{\mathrm{g}}$ & $25.28 \pm 0.56^{\mathrm{d}}$ & 3.30 & 92.99 \\
\hline & $1.0 \%$ & $38.60 \pm 0.94^{\mathrm{b}}$ & $2.37 \pm 0.13^{h}$ & $23.99 \pm 0.49^{b}$ & 5.67 & 94.72 \\
\hline \multirow{3}{*}{$\begin{array}{l}\text { Calcium } \\
\text { citrate }\end{array}$} & $0.1 \%$ & $45.38 \pm 1.43^{f}$ & $1.25 \pm 0.22^{\mathrm{d}}$ & $27.02 \pm 0.68^{\mathrm{h}}$ & 1.66 & 87.43 \\
\hline & $0.5 \%$ & $46.84 \pm 1.38^{g}$ & $0.58 \pm 0.27^{\mathrm{b}}$ & $27.42 \pm 0.61$ & 2.88 & 84.84 \\
\hline & $1.0 \%$ & $47.66 \pm 1.39^{\mathrm{h}}$ & $0.25 \pm 0.24^{\mathrm{a}}$ & $27.69 i 0.60^{1}$ & 4.54 & 81.85 \\
\hline \multirow{3}{*}{$\begin{array}{l}\text { Calcium } \\
\text { acetate }\end{array}$} & $0.1 \%$ & $43.39 \pm 1.32^{\mathrm{e}}$ & $1.59 \pm 0.51^{\mathrm{e}}$ & $26.07 \pm 0.58^{\mathrm{f}}$ & 0.35 & 89.42 \\
\hline & $0.5 \%$ & $41.12 \pm 1.35^{\mathrm{c}}$ & $1.82 \pm 0.24^{\mathrm{f}}$ & $24.94 \pm 0.66^{\mathrm{c}}$ & 3.34 & 91.47 \\
\hline & $1.0 \%$ & $37.03 \pm 1.27^{\mathrm{a}}$ & $2.34 \pm 0.16^{\mathrm{h}}$ & $22.91 \pm 0.65^{\mathrm{a}}$ & 7.62 & 94.33 \\
\hline \multirow{3}{*}{$\begin{array}{l}\text { Calciuin } \\
\text { carbonate }\end{array}$} & $0.1 \%$ & $44.02 \pm 1.35^{\mathrm{e}}$ & $1.09 \pm 0.25^{\mathrm{cd}}$ & $26.27 \pm 0.61^{\mathrm{f}}$ & 1.12 & 87.14 \\
\hline & $0.5 \%$ & $45.64 \pm 1.29^{f}$ & $0.64 \pm 0.47^{\mathrm{b}}$ & $26.63 \pm 0.5^{\mathrm{g}}$ & 1.35 & 90.29 \\
\hline & $1.0 \%$ & $45.86 \pm 1.41^{\mathrm{f}}$ & $0.97 \pm 0.3 \mathrm{l}^{\mathrm{c}}$ & $27.03 \pm 0.61^{\mathrm{h}}$ & 1.76 & 86.51 \\
\hline
\end{tabular}

${ }^{\mathrm{a}-j}$ Values followed by a different superscript letters are significantly different $(\mathrm{p}<0.05)$ among each parameter 011 the same column. $\mathrm{I}^{*} 6^{*}$ values represent mean $\pm \mathrm{SD}$ (ii=3).

The colour difference $\Delta \mathrm{E}$ values of $0.5 \%$ and $1.0 \%$ calcium lactate and acetate as compared to the value of the control model cookies were all higher than 3 (Table 3). This indicated that the difference between the control model cookies and fortified model cookies was readily apparent. Higher $\mathrm{L}^{*}, \mathrm{~b}^{*}$ and lower brown index values of model cookies fortified with calcium citrate and calcium carbonate were recorded and compared to the control model cookies. The colour difference $\Delta \mathrm{E}$ values of $0.5 \%$ and $1.0 \%$ calcium citrate-fortified cookies compared to the value of the control model cookies were higher than 2 (Table 3). Cookies formulated with different amounts of calcium carbonate had surface colour and brown index values comparable to those of the control model cookies. In contrast, the difference was easily noticed when $1 \%$ of other calcium salts was added to the cookie formulation; the difference in CIEL*a*b* values was significant. The colour of cookies fortified with calcium citrate or calcium carbonate was lighter. On the contrary, the color of cookies fortified with calcium lactate or calcium acetate was darker in comparison to the control cookies. A darker colour was observed for the groups treated with $0.5 \%$ calcium lactate.

The water activity of the control cookies and control model cookies was 0.268 and 0.356 , respectively. The maximum water activity reduction was detected for model cookies and cookies fortified with $1.0 \%$ calcium acetate. The level of water activity in all the control cookies and fortified cookies was low enough from a food safety consideration. Comparing the control cookies and model cookies, the addition of calcium salts at an amount higher than $0.1 \%$ significantly increased the ash content in the cookies $(\mathrm{p}<0.05)$.

The darkest model cookie colour was observed for the $1.0 \%$ calcium acetate treatment group. The browning index of model cookies treated with $1.0 \%$ calcium acetate was more intense than those treated with $1.0 \%$ calcium carbonate, which contained the lowest acrylamide content. Nevertheless, the degree of browning was not closely related to the formation of acrylamide in baking products with different calcium salts. Our results were in agreement with those reported by Jung et al. [12], i.e., that the browning degree of baked corn chips treated with citric acid was not directly related with the acrylamide concentration in the corn chips. The $\mathrm{pH}$ of the model cookies and cookies increases with increases in the fortification level of calcium acetate.
The acrylamide content of the treated model cookies significantly decreased with an increase in calcium acetate fortification. This implied that the acrylamide concentration in the baked model cookies was reduced by fortifying the cookie dough with calcium acetate, calcium citrate or calcium carbonate. Our results suggested that the effect of the interactions between calcium cations and reducing sugar in the model cookies dominated the factor of cookie dough $\mathrm{pH}$.

Both calcium lactate- and calcium acetate-fortified groups produced model cookies and cookies with darker surface browning and interiors. Supplementing the cookie dough with calcium lactate and calcium acetate significantly decreased cookie diameter and thickness (Table 2). The cookie spread ratio increased with increases in the amount of calcium lactate or calcium acetate. The addition of calcium lactate or calcium acetate to the cookie recipe decreased the surface lightness $\left(\mathrm{L}^{*}\right)$, but increased the brown index. As a result, the total colour difference dramatically increased in both fortified cookies.

\subsection{Sensory Evaluation of Fortified Cookie}

There was no significant difference in the odour and sweetness scores between control cookies and cookies fortified with various amounts of calcium carbonate (Table 4). The sensory panellists determined no differences in cookie odour and sweetness at a dosage of $1.0 \%$ calcium carbonate with the control cookie. The addition of calcium carbonate to the cookies affected neither the flavor nor the taste. Calcium carbonate addition at the level of $1 \%$ resulted in higher texture, colour and overall scores than that of the control cookies. The sensory panellists preferred a harder texture and a lighter cookie colour. Of the calcium salts evaluated in this study, calcium carbonate was the most effective supplement in terms of the reduction of acrylamide formation; it was also acceptable at a dosage of $1 \%$ according to sensory evaluation results. Our results corresponded well with the report of Mestdagh et al. [30], which stated that calcium lactate and calcium chloride at a dosage of $1 \%$ resulted in a saltier and less sweet taste than control cookies. Our results also agreed with the report of Acar et al. [7], in that calcium carbonate addition gave a higher texture score than that of the control cookies (Table 4). 
Table 4. Effects of different ainoiints of calcium carbonate on sensory evaluation of the cookies

\begin{tabular}{|c|c|c|c|c|c|}
\hline Cookies & Odour & Colour & Texture & Sweetness & Overall acceptability \\
\hline Control & $4.96 \pm 1.09^{\mathrm{a}}$ & $5.07 \pm 1.11^{\mathrm{a}}$ & $4.95 \pm 1.31^{\mathrm{a}}$ & $5.20 \pm 1.17^{\mathrm{a}}$ & $5.04 \pm 1.01^{\mathrm{a}}$ \\
\hline $0.1 \%$ & $5.14 \pm 1.33^{\mathrm{a}}$ & $5.09 \pm 1.12^{\mathrm{a}}$ & $5.18 \pm 1.06^{\mathrm{ab}}$ & $5.07 \pm 1.29^{\mathrm{a}}$ & $5.27 \pm 1.07^{\mathrm{ab}}$ \\
\hline $0.5 \%$ & $5.04 \pm 1.14^{\mathrm{a}}$ & $5.11 \pm 1.07^{\mathrm{a}}$ & $5.14 \pm 1.23^{\mathrm{ab}}$ & $5.05 \pm 1.29^{\mathrm{a}}$ & $5.04 \pm 1.09^{\mathrm{a}}$ \\
\hline $1.0 \%$ & $5.30 \pm 1.14^{\mathrm{a}}$ & $5.50 \pm 1.10^{\mathrm{b}}$ & $5.36 \pm 1.05^{\mathrm{b}}$ & $5.39 \pm 1.07^{\mathrm{a}}$ & $5.54 \pm 0.93^{\mathrm{b}}$ \\
\hline
\end{tabular}

${ }^{\mathrm{a}-\mathrm{l}}$ Values with the different letters within the same column are significantly different at $\mathrm{p}<0.1$. Mean \pm SD ( $\mathrm{n}=56$ ). $1-7$ scale: $1=$ dislike very much. 7 $=$ like very much.

\section{Conclusion}

Calcium salt fortification significantly reduced acrylamide formation and reducing sugar levels in model cookies and cookies when the amount of calcium salts was increased from $0.1 \%$ to $1.0 \%$. Calcium salts decreased the water activity, but increased the ash content and hardness of the cookies. In addition, the reducing sugar contents of the cookies and model cookies were also decreased by the addition of calcium ions. Fortification of cookies with calcium lactate and calcium acetate produced darker coloured cookies, while the addition of calcium citrate and calcium carbonate addition to the cookie recipe led to a lighter colour. The formation of acrylamide showed a positive correlation with the reducing sugar concentration of the calcium salt-fortified cookies and the model cookies. Calcium carbonate added at a dosage of $1 \%$ to the cookie dough was the most effective in reducing acrylamide formation in model cookies and cookies by $60 \%$ and $44 \%$, respectively. However, the degree of browning was not closely related with the formation of acrylamide in cookies fortified with different calcium salts. Fortification of cookies with calcium carbonate had no negative effect on the sensory scores. The overall acceptability of cookies fortified with $1 \%$ calcium carbonate was higher than that of the control cookies. Calcium carbonate addition at a dosage of $1 \%$ could lead to better cookie qualities and so become the top calcium supplement for the baking industry.

\section{Acknowledgement}

The authors would like to thank the National Taiwan Ocean University and Center of Excellence for the Oceans which financed this research.

\section{References}

[1] Lineback DR, Coughlin JR, Stadler RH. Acrylamide in : A review of the science and future considerations. The Annual Review of Food Science and Technology 3: 15-35, 2012.

[2] Tareke E, Rydberg R, Karlsson P, Ericksson S, Tornqvist, M. Analysis of acrylamide, a carcinogen formed in heated foodstuffs. J Agr Food Chem 50: 4998-5006, 2002.

[3] Yasahura A, Tanaka Y, Hengel M, Shibamoto, T. Gas chromatographic investigation of acrylamide formation in browning model system. J Agr Food Chem 51: 3999-4003, 2003.

[4] Zyzak D, Sanders RA, Stojanovic M, Tallmadge, DH, Ebehart L, Ewald DK, Gruber DC, Morsch TR, Strothers MA, Rizzi GP, Villagran MD. Acrylamide formation mechanism in heated foods. J Agr Food Chem 51: 4782-4787, 2003.
[5] Tareke E, Rydberg P, Karlsson P, Eriksson S, Tornqvist M. Acrylamide: a cooking carcinogen? Chem Res Toxicol 13: 517522, 2000.

[6] Becalski A, Lan BPY, Lewis D, Seaman SW. Acrylamide in foods: occurrence, sources, and modeling. J Agr Food Chem 51: 802-808, 2003.

[7] Acar OC, Pollio M, Monaco RD, Fogliano V, Gokmen V. Effect of calcium on acrylamide level and sensory properties of cookies. Food Bioprocess Tech 5: 519-526, 2012.

[8] Mottram DS, Wedzicha BL, Dodson AT. Acrylamide is formed in the Miallard reaction. Nature 419: 448-449, 2002.

[9] Stadler RH, Blank I, Verga N, Robert F, Han J, Guy PA, Robert M, Riediker S. Acrylamide from Maillard reaction products. Nature 419: 449-450, 2002.

[10] Rydberg P, Eriksson S, Tareke E, Karlsson P, Ehrenberg L, Tornqvist $M$. Investigations of factors that influence the acrylamide content of heated foodstuffs. J Agr Food Chem 51: 7012-7018, 2003.

[11] Gokmen V, Senyuva HZ. Effects of some cations on the formation of acrylamide and furfurals in glucose-asparagine model system. Eur Food Res Technol 225: 815-820, 2007.

[12] Jung MY, Choi DS, Ju JW. A novel technique for limitation of acrylamide formation in fried and baked corn chips and in French fries. J Food Sci 68: 1287-1290, 2003.

[13] Lindsay RC, Jang S. Chemical intervention strategies for substantial suppression of acrylamide formation in fried potato products. Adv Exp Med Biol 561: 393-404, 2005.

[14] Gokmen V, Senyuva HZ. Acrylamide formation is prevented by diavalent cations during the Maillard reaction. Food Chem 103: 196-203, 2007.

[15] Gokmen V, Acar OC, Koksel H, Acar J. Effects of dough formula and baking conditions on acrylamide and hydroxymethylfurfural formation in cookies. Food Chem 2007; 104: 1136-1142.

[16] Gokmen V, Akbudak B, Serpen A, Acar J, Turan ZM, Eris A. Effects of controlled atmosphere storage and low-dose irradiation on potato tuber components affecting acrylamide and color formations upon frying. Eur Food Res Technol 224: 681-687, 2007.

[17] Amrein TM, Schonbachler B, Escher F, Amado R. Acrylamide in gingerbread: critical factors for formation and possible ways for reduction. J Agr Food Chem 52: 4282-4288, 2004.

[18] Brathen E, Kita A, Knutsen SH, Wicklund T. Addition of glycine reduces the content of acrylamide in cereal and potato products. $J$ Agr Food Chem 53: 3259-3264, 2005.

[19] Pedreschi F, Kaack K, Granby K. The effect of asparaginase on acrylamide formation in French fries. Food Chem 109: 386-392, 2008.

[20] Ciesarova Z, Kiss E, Boegl P. Impact of L-asparaginase on acrylamide content in potato products. J Food Nutr Res 45: 141146, 2006.

[21] Biedermann M, Grob K. Model studies on acrylamide formation in potato, wheat flour and corn starch; ways to reduce acrylamide contents in bakery ware. Mitteilungen aus Lebensmitteluntersuchung und Hygiene 94: 406-422, 2003.

[22] AACC. Approved methods of the American Association of Cereal Chemists. $10^{\text {th }}$ ed. St. Paul, Minnesota, 2000.

[23] Hwang JY, Sung WC, Shyu YS. Effect of mulberry lees addition on dough mixing characteristics and the quality of mulberry toast. J Mar Sci Technol-TA 16: 103-108, 2008.

[24] Ilyina AV, Tikhonov VE, Albulov AI, Varlamov VP. Enzymic preparation of acid-free-water soluble chitosan. Process Biochem 35: 536-568, 2000. 
[25] Clawson AR, Taylor AJ. Chemical changes during cooking of wheat. Food Chem 47: 337-343, 1993.

[26] Hamlet CG, Sadd PA. Effects of yeast stress and $\mathrm{pH}$ on 3monchloropropanediol (3-MCPD)-producing reactions in model dough systems. Food Addit Contam 22: 616-623, 2005.

[27] Levin RA, Ryan SM. Determining the effect of calcium cations on acrylamide formation in cooked wheat products using a model system. J Agr Food Chem 57: 6823-6829, 2009.
[28] Clydesdale FM. Minerals: Their Chemistry and Fate in Food. In: Smith K, editor. Trace Minerals in Food. Marcel Dekker, New York, 1988, p. 57-94.

[29] Sadd PA, Hamlet CG, Liang L. Effectiveness of methods reducing acrylamide in bakery products. J Agr Food Chem 56: 6154-6161, 2008.

[30] Mestdagh E, De Wilde T, Deporte K, Van Peteghem C, De Meulenaer B. Impact of chemical pre-treatments on the acrylamide formation and sensorial quality of potato crisps. Food Chem 106: 914-922, 2008. 